\title{
Treatment and Outcome of Chronic Subdural Hematoma in Sub-Saharan Africa and the Country of Benin
}

\author{
Luphin Hode ${ }^{1 *}$, Kisito Quenum ${ }^{2}$, Holden O. Fatigba ${ }^{3}$, Lionelle Fanou ${ }^{2}$, Henderson G. S. Lansdale ${ }^{4}$ \\ ${ }^{1}$ Neurosurgeon, Emergency Service, National University Hospital Center Hubert Koutoukou Manga of Cotonou, Africa \\ ${ }^{2}$ Neurosurgeon, Unit of Neurosurgery, Army Training Hospital of Cotonou, Africa \\ ${ }^{3}$ Neurosurgeon, Unit of neurosurgery, Departmental Teaching Hospital of Borgou/Alibori, Benin, Africa \\ ${ }^{4}$ Graduate Institute, St. John's College, Annapolis, US \\ * Corresponding Author: Department Neurosurgeon, Emergency service, National University Hospital Center Hubert Koutoukou Manga \\ of Cotonou, Africa. Tel:+229 67228626, Fax: +229213016 63, Email: luphin@gmail.com
}

Article Type: Research Article

Received: August 14, 2015, Last revised: September 19,2015, Accepted: September 22, 2015

\section{Abstract}

Background \& Aim: Chronic subdural hematoma (CSDH) is a common neurosurgical pathology. The objective of this study was to describe the epidemiology of this pathology and the results in treating it combined from three hospital centers in Benin.

Methods \& Materials/Patients: From September 2010 to September 2013 a multi-center, retrospective and descriptive study was conducted in three hospital centers in Benin. Inventory was taken of all patients in whom CSDH was diagnosed. Patients were evaluated according to Markwalder classification. All patients received a brain scan. The variables studied include demographic and clinical characteristics, therapeutic modalities and post-operative followup.

Results: 104 consecutive patients with CSDH were included in the study. The mean age was 49.66, but ranged from six months to 87 years. The M:F sex ratio was 5.11/1. Prior cranial trauma had occurred in 81 patients (77\%). Preoperative neurological Grades 1 or 2 were observed in $56.4 \%$ of cases. Surgical treatment was given to 100 patients $(96.15 \%)$. Events surrounding the surgery were straightforward and results satisfactory in $94 \%$ of cases. No relapses were observed. The morbidity was $4 \%$ and the mortality among surgical patients was $3 \%$.

Conclusion: $\mathrm{CSDH}$ is frequently treated in the country of Benin. The mean age of patients is lower than that observed in global literature, and patients are predominantly male. Regardless of the patient condition upon hospital admission, post-operative results compare favorably with the literature.

Keywords: Chronic; Subdural hematoma; Cranial Trauma; Africa; Benin

Please cite this paper as: Hode L, Quenum K, Fatigba O. H, Fanou L, Lansdale G.S.H. Treatment and Outcome of Chronic Subdural Hematoma in Sub-Saharan Africa and the Country of Benin. Iran. J. Neurosurg. 2015;1(2):31-35.

\section{Introduction}

Chronic subdural hematoma $(\mathrm{CSDH})$ is a common pathology in neurosurgery. It is the consequence of a venous hemorrhage in the subdural space, most often following minor cranial trauma (1). The asymptomatic time interval between the moment of trauma, which may occur unnoticed by the patient, and the first symptom may exceed several weeks. This pathology was described for the first time in 1658 by Johann Jacob Wepfer (2). Since then, several risk factors have been identified: age, cortico-subcortical atrophy, intracranial hypotension, hemostatic disorders and chronic alcoholism. Epidemiologically, incidence of SDH as reported in Western literature increases with age, from 3.4/100,000 among patients below the age of 65 to $58.1 / 100,000$ above the age of $65(3,4)$.

There have been several African publications (5-10) within the larger global literature on this disorder. This primary study from the country of Benin seeks to describe and compare the epidemiological profile of CSDH as well as our post-operative results relative to that of other countries.

\section{Methods and Materials/Patients}

Benin is a low-income francophone country in West Africa (Figure 1). The population is 10.6 million in habitants in 2014 and the Gross Domestic Product (GDP) is \$8.307 billion USD in 2013. The revenue per inhabitant was $\$ 790$ USD per year, and the poverty rate was $36.2 \%$ in 2013 . Life expectancy was 59 years old in 2012 according to the World Bank (11). Benin has a three-tiered pyramidal health system. The National University Hospital Center Hubert Koutoukou Manga "Centre National Hospitalier Universitaire Hubert, Koutoukou Manga" in Cotonou and University Hospital Center of Parakou "Centre Hospitalier Universitaire Departmental of Borgou/Alibori" are the two national-level university hospitals. The Army Training Hospital of Cotonou 'l'Hôpital d'Instruction des Armées" is a department or region-level hospital. Benin has 
six practicing neurosurgeons, among whom five practice in Cotonou, Benin's largest city, and one practices in Parakou, the third largest city situated $450 \mathrm{~km}$ north of Cotonou. We present a multi-center, retrospective study conducted in three hospital centers in Benin, each with a participating neurosurgeon: the "Centre National Hospitalier Universitaire Hubert Koutoukou Manga" (CNHU-HKM) and "l'Hôpital d'Instruction des Armées" (HIA) in Cotonou, and the "Centre Hospitalier Universitaire Départemental de Borgou/Alibori " (CHUD-B/A) in Parakou. Every CSDH case admitted between September 2010 and September 2013 was studied. Each patient received a non-contrasted computed tomography (CT) scan of head. The chronicity of the lesion was defined by Hounsfield unit density and designated either iso- or hypo- dense. Each patient underwent focused clinical examination that assessed for recent history of cranial trauma, anticoagulant use, changes in consciousness, and neurological deficits. The neurological state of patients was evaluated according to the Markwalder classification (12): Grade 0: no symptoms; Grade 1: moderate symptoms (cephalgia) or slight deficits (reflex asymmetry); Grade 2: confusion or spatio-temporal disorientation with neurological deficits (hemiparesis); Grade 3: stuporous but responsive to painful stimulus; Grade 4: coma without motor response to painful stimulus, decerebrate or decorticate posturing. Grades 0-2 have a favorable prognosis and Grades 3 and 4 have an unfavorable prognosis. The technique of single or double burr-hole trephination or a cranial flap was chosen according to the surgeon's preference and scan assessment. Interventions were conducted under general anesthesia or local anesthesia for unilateral CSDH according to the judgment of the surgical team. General anesthesia was systematically used for bilateral CSDH. Hematoma evacuation was achieved by trephining a single or double burr-hole followed by a subdural cavity wash with physiological saline. Each surgical patient received $1.5 \mathrm{~g}$ prophylactic Cefuroxime. A subdural drain was left in place for 48 hours post-surgery. The surgical treatment was completed by hyperhydration, and the patient was kept in strict dorsal decubitus for 48 hours. Post-operative care was largely based on clinical evaluation of language consciousness and motor deficit. CT scan verification was ordered according to clinical progression and the financial means of the patient. The variables studied were socio-demographics, medical history and risk factors, clinical exam findings, post-operative progression and fatality. Statistical analysis and data processing were performed with the software epi Info (Version 3.2.2).

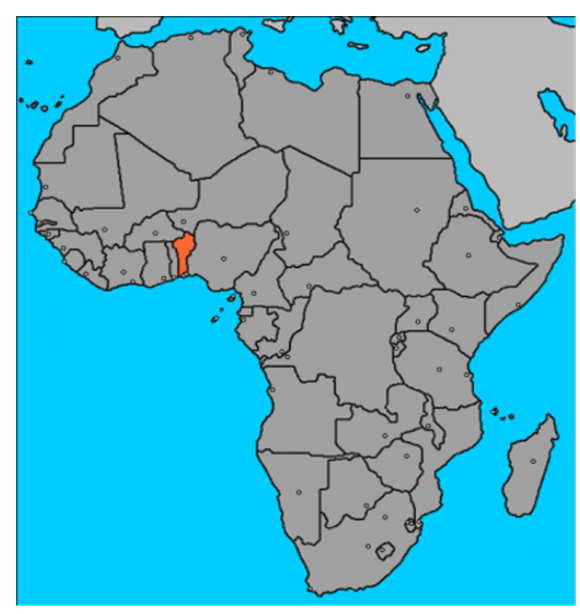

Figure 1. The Position of Benin on a Map of Africa

\section{Results}

104 patients diagnosed with CSDH were considered for inclusion in the study. This patient population was composed of 87 men (83.65\%) and 17 women (16.35\%); the sex ratio was just over 5:1. The mean age of patients was $49.66 \pm 14.46$ years ranging from six months to 87 years of age. Prior cranial trauma was identified in 81 patients $(77.88 \%)$, and coagulation complications were identified in 8 patients $(7.70 \%)$. In 15 cases (14.42\%), no etiology or contributing factors were identified. Alterations in state of consciousness in 87 cases $(83.65 \%)$ and the presence of a neurological deficit in 97 cases $(93.26 \%)$ were the primary grounds for patient admission. The distributions of signs identified during examination among the 104 patients are reported in Table 1. According to the Markwalder classification, $56.73 \%$ of patients (59) were Grades 1 or 2, and $43.27 \%(45)$ were Grades 3 or 4 . Radiological examination revealed 44 cases $(42.30 \%)$ of $\mathrm{CSDH}$ in the left hemisphere, 42 cases $(40.38 \%)$ in the right hemisphere (Figure 2), and 18 cases $(17.30 \%$ ) of bilateral CSDH (Figure 3). Surgery was indicated in 100 patients (96.15\%). Among the four non-surgical patients, three received medical treatment including a three-week course of prednisone, and the fourth patient received medical surveillance. During surgery, 77 patients $(74.04 \%)$ received general anesthesia and $23(22.12 \%)$ received local anesthesia. The surgical technique consisted of a single burr-hole trephination for 52 patients (52\%), double burr-hole trephination for 47 patients $(47 \%)$, and a five-hole bone flap in one patient (1\%). Each patient systematically underwent 48 hours of drainage and rehydration. The surgical proceedings and results were straight-forward and satisfactory in 94 patients (94\%). Clinical progression over a three-month period is summarized in Table 2. No cases of relapse were observed. Post-operative morbidity was 4\% (4 patients) including one case of thrombophlebitis, and three cases of parietal infection including one case of subdural empyema. The two cutaneous infections advanced despite antibiotic treatment. The empyema required surgical evacuation and antibiotic treatment. The total mortality among the surgical patients was 3\% (3/100); all of these patients had been classified as Markwalder Grade 4 before surgical intervention. One died following a post-operative complication of acute contro-lateral subdural hematoma, one patient died maintaining the same pre-operative neurological state, and the third patient died of infectious circumstances.

Table 1. Distribution according to Markwalder Classification

\begin{tabular}{|c|l|c|}
\hline Grade & \multicolumn{1}{|c|}{ Symptoms } & Number (\%) \\
\hline 0 & No symptoms & $00(0)$ \\
\hline 1 & $\begin{array}{l}\text { Moderate symptoms (cephalgia) or light } \\
\text { deficits (reflex assymetry) }\end{array}$ & 42 (40.38) \\
\hline 2 & $\begin{array}{l}\text { Spatio-temporal confusion or disorienta- } \\
\text { tion with neurological deficits (hemipa- } \\
\text { resis) }\end{array}$ & $39(37.50)$ \\
\hline 3 & $\begin{array}{l}\text { Stuporous but responsive to painful stim- } \\
\text { ulus; severe focal signs (hemiplegia) }\end{array}$ & $6(5.76)$ \\
\hline 4 & $\begin{array}{l}\text { Coma without motor response to painful } \\
\text { stimuli ; decerebrate or decorticate pos- } \\
\text { turing }\end{array}$ & \\
\hline
\end{tabular}

Table 2. Overview of Clinical Progression

\begin{tabular}{|l|c|c|c|}
\hline Clinical Criteria & Improved & Unchanged & Aggravated \\
\hline Consciousness & 91 & 4 & 2 \\
\hline Language & 96 & 0 & 1 \\
\hline Motor Deficits & 93 & 4 & 0 \\
\hline
\end{tabular}




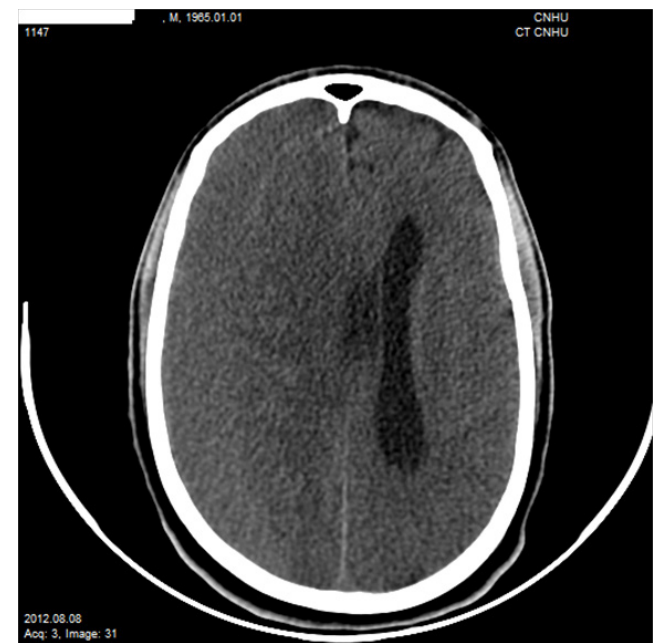

Figure 2. Chronic Subdural Hematoma in the Right Hemisphere

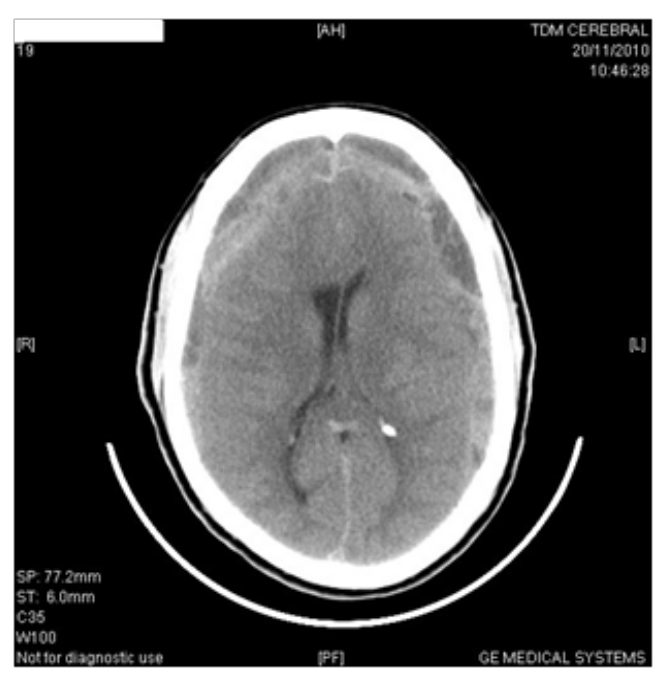

Figure 3. Bilateral Chronic Subdural Hematoma

\section{Discussion}

The treatment of SDH is a commonplace neurosurgical intervention (13). This study conducted in Benin permitted us to focus on this intervention and compare our results to the published literature, notably to African authors practicing in conditions similar to ours. The three hospital centers chosen are model public hospitals, with regular usage of CT scanners and, albeit recent, neurosurgical capabilities. Although a considerable number, 104 patients are short of the reality. The diagnosis was based on the CT scan as well as accessibility of patients to this exam, which was restricted by its cost. As reported by an earlier study by Fatigba et al.(14), such limited access to brain examination is a major diagnostic obstacle in low-income countries. Several African authors have reported their experiments in CSDH treatment (5-10). These authors reveal $\mathrm{CSDH}$ to be relatively frequent among neurosurgical services in Africa as with elsewhere in the world $(4,15,16)$. The mean age of CSDH patients in sub-Saharan Africa is less than 60 years according to most publications $(6,7,10)$. This is due to the relative youth of the sub-Saharan population and its shorter life expectancy. In our study as with other sub-Saharan publications, cranial trauma is the most frequent cause of CSDH (Table 3 ). The predominance of males participating in our study, as with other studies, is probably due to the fact that men are exposed to more trauma than females (17). The majority of our patients $(88.68 \%)$ presented with a unilateral hematoma and $17.30 \%$ presented with a bilateral hematoma. The predominance of unilateral hematoma was also reported by Bacchli et al. (78\% vs 22\%) (17), Gelabert-Gonzalez et al. (90.3\% vs 9.7\%) (4), and Hima-Maiga et al. (77.38\% vs $22.72 \%$ ) (8). Despite its frequency, CSDH presents many pathophysiological problems. The pathophysiology of CSDH is not well-elucidated, though the most widely accepted explanation is that of repeated bleeding from the external membrane of the hematoma $(18,19)$. There is also an active inflammatory phenomenon. The macrocapillaries present on the external membrane of the hematoma share the characteristics of vessels found in inflammatory tissue with the capacity for augmented bleeding $(20,21)$. The hematoma contains high concentrations of vaso-active cytokines, inflammatory mediators and fibrinolytic factors (22-27). It is precisely on this inflammatory storm that corticoids take action. Glucocorticoids such as cortisol also have a discrete but demonstrated mineralocorticoid activity promoting water and sodium retention and potassium escape. This activity could be invoked to explain cerebral water retention, which exacerbates the expansion of cerebral parenchyma against the osseous wall. In 1974, Bender published a study of 27 patients treated with prednisone, and those who responded favorably were classified as Grade 0 or 1(28); prednisone was not indicated in three patients experiencing only a headache (Markwalder Grade 1).

Table 3. Comparison of Socio-demographic Characteristics and Causes of CSDH in Sub-Saharan Africa

\begin{tabular}{|c|c|c|c|c|c|c|c|}
\hline Authors (City) & $\begin{array}{c}\text { MWANYOBE } \\
\text { OMPOUGA }{ }^{24} \\
\text { (Libreville) }^{24}\end{array}$ & $\begin{array}{l}\text { BANKOLE }^{2} \\
\text { (Lagos) }\end{array}$ & $\begin{array}{c}\text { DJIENTCHEU } 5 \\
\text { (Duala) }\end{array}$ & $\begin{array}{l}\text { DAKURAH }{ }^{4} \\
\text { (Accra) }\end{array}$ & $\begin{array}{l}\text { MEZUE } 23 \\
\text { (Enugu) }\end{array}$ & $\begin{array}{l}\text { HIMA } \\
\text { MAIGA }^{16} \\
\text { (Dakar) }^{\text {Dak }}\end{array}$ & $\begin{array}{c}\text { OUR STUDY } \\
\text { (Cotonou, } \\
\text { Parakou) }\end{array}$ \\
\hline Number of patients & 102 & 73 & 195 & 96 & 116 & 88 & 104 \\
\hline Duration of study & $1998-2008$ & $2005-2010$ & $2000-2008$ & $1995-1998$ & - & $2005-2009$ & $2010-2013$ \\
\hline Sex ratio & $4 / 1$ & $7.1 / 1$ & $3.8 / 1$ & $16 / 1$ & $3 / 1$ & $7 / 1$ & $5.11 / 1$ \\
\hline Mean age & 58 & $60-71$ & 55 & 47 & $>60$ & 67 & 49.66 \\
\hline Cranial trauma & $64 \%$ & $64 \%$ & $81 \%$ & $64.7 \%$ & $72.3 \%$ & $56.91 \%$ & $77 \%$ \\
\hline $\begin{array}{l}\text { Problematic coag- } \\
\text { ulation }\end{array}$ & - & $2.7 \%$ & $4.1 \%$ & - & $16.8 \%$ & - & $7.6 \%$ \\
\hline Chronic alcholism & - & - & $12.5 \%$ & - & - & $00 \%$ & - \\
\hline Unknown cause & $16 \%$ & - & - & - & - & - & $14.42 \%$ \\
\hline
\end{tabular}


Table 4. Comparison of Treatment and Result CSDH in Sub-Saharan Africa

\begin{tabular}{|l|c|c|c|c|c|c|c|}
\hline \multicolumn{1}{|c|}{ Authors (City) } & $\begin{array}{c}\text { MWANYOBE } \\
\text { OMPOUGA } \\
\text { (Libreville) }\end{array}$ & $\begin{array}{c}\text { BANKOLE } \\
\text { (Lagos) }\end{array}$ & $\begin{array}{c}\text { DJENTCHEU 5 } \\
\text { (Duala) }\end{array}$ & $\begin{array}{c}\text { D A K U R A H } \\
\text { (Accra) }\end{array}$ & $\begin{array}{c}\text { MEZUE 23 } \\
\text { (Enugu) }\end{array}$ & $\begin{array}{c}\text { HIMA } \\
\text { MAI- } \\
\text { GA } \\
\text { (Dakar) }\end{array}$ & $\begin{array}{c}\text { OUR STUDY } \\
\text { (Cotonou, } \\
\text { Parakou) }\end{array}$ \\
\hline $\begin{array}{l}\text { Single burr-hole } \\
\text { trephination }\end{array}$ & $0 \%$ & $96 \%$ & $92.4 \%$ & $84 \%$ & - & $98 \%$ & $52 \%$ \\
\hline $\begin{array}{l}\text { Double burr-hole } \\
\text { trephination }\end{array}$ & $87 \%$ & $0 \%$ & $3.6 \%$ & $0 \%$ & - & $1.13 \%$ & $47 \%$ \\
\hline Cranial flap & $13 \%$ & $4 \%$ & $4 \%$ & $16 \%$ & - & $00 \%$ & $1 \%$ \\
\hline Satisfactory results & $94 \%$ & $91.3 \%$ & $96 \%$ & - & $87 \%$ & $92.04 \%$ & $94 \%$ \\
\hline Morbidity & - & $6.8 \%$ & $1 \%$ & - & - & $5 \%$ & $4 \%$ \\
\hline Mortality & - & $12.5 \%$ & $3.7 \%$ & $2 \%$ & $7.8 \%$ & $3.97 \%$ & $3 \%$ \\
\hline Relapse & $6 \%$ & $6.3 \%$ & $2.6 \%$ & $2 \%$ & $0.8 \%$ & $10 \%$ & $0 \%$ \\
\hline
\end{tabular}

The results from this treatment were satisfactory with a decrease in both cephalgia and of the size of hematoma based on CT scan analysis. Surgery is indicated for symptoms of CSDH (29). The aim of the surgery is to evacuate a compressive hematoma. Since Putman and Cushing in 1925, the standard surgical treatment has been a craniotomy with a membranectomy (30). The technique gradually advanced to include rinsing of the hematic cavity with physiological saline $(31,32)$ and post-operative drainage for 1 to 3 days (33). Eventually, upon noticing that the content of these hematomas was becoming more fluid by the time of clinical manifestation, the technique was altered to reduce the size of the surgical approach. In 1960, McKissoch described the technique of single or double burr-hole trephination (34) and, in 1977, Tabaddor and Shulman described the technique of "twistdrill" (35). Endoscopy-assisted evacuation of the hematoma was described by Drapkin in 1977 (36). The positioning of a subdural peritoneal bypass was developed by Probst in 1988 (37). Craniectomy is used for recurring or compartmentalized hematomas and in the case of complication due to subdural empyema (33). One subject in this study underwent craniectomy once for a subdural collection in a febrile context that precipitated a subdural empyema. The technique of single or double burrhole trephination is more frequently used, less invasive, and can be performed under local anesthesia (38). In our study, the single and double burr-hole trephination techniques were the most frequently used. However, single burr-hole trephination remains the predominant technique according to the majority of sub-Saharan publications (Table 4). In this study, we achieved satisfactory results in $94 \%$ of patients, despite the elevated frequency of patients (43.61\%) admitted with a poor preoperative neurological prognosis. Our results can be compared favorably with those of other sub-Saharan studies. These results may be associated with the lower mean age of African population. The mortality was 3\%. It was attributed to a neurological cause in two subjects, and to a general cause in one. Other African studies demonstrate a mortality rate similar to those observed elsewhere in the world, including India (15), Spain (4) and Brazil (16) Notwithstanding, the mortality was twice the rate in Nigerian studies conducted in Lagos (5) and Enugu (9). Finally, the immediate post-operative morbidity was $4 \%$. Morbidity was due to infectious as well as decubitus complications, similar to findings by other African authors.

\section{Conclusion}

Chronic subdural hematoma is a common neurological disorder. Despite its apparent pathogenic and therapeutic simplicity, its prognosis remains uncertain. In sub-Saharan studies, life expectancy was lower than in developed countries. CSDH was observed predominantly among men, and the primary cause was cranial trauma. The surgical treatment was based on single or double burr-hole trephination. Post-operative results were satisfactory compared to those observed elsewhere in the world.

\section{Funding}

None.

\section{Conflicts of Interest}

The authors affirm that they have no conflicts of interest.

\section{References}

1. Haines DE, Harkey, H.L., al-Mefty, O. The "subdural" space : a new look at an outdated concept. Neurosurgery 1993;32:111-20.

2. Hoessly G.F. Intracranial hemorrhage in the 17th century. A reappraisal of Johann Jacob Wepfer's contribution regarding subdural hematoma. J Neuro-surg 1966;24:493-96.

3. Ducruet AF, Grobelny BT, Zacharia BE, Hickman ZL, DeRosa PL, Anderson $\mathrm{K}$, et al. The surgical management of chronic subdural hematoma. Neurosurg Rev. 2012;35(2):155-69; discussion 69.

4. Gelabert-Gonzalez M, Iglesias-Pais M, Garcia-Allut A, Martinez-Rumbo R. Chronic subdural haematoma: surgical treatment and outcome in 1000 cases. Clinical neurology and neurosurgery. 2005;107(3):223-9.

5. Bankole O B YAS, Kanu O O, Ukponmwan E N M N, Arigbabu S O. chronic subdural haematoma: clinical presentation, surgical treatment and outcome at the lagos university teaching hospital. AJNS. 2011;30(1):10-7.

6. Dakurah TK, Iddrissu M, Wepeba G, Nuamah I. Chronic subdural haematoma: review of 96 cases attending the Korle Bu Teaching Hospital, Accra. West African journal of medicine. 2005;24(4):283-6.

7. Djientcheu V. P. EA, Yamgoue T., Tchaleu B., Ze Minkande J. Surgical treatment and outcome of 195 cases of non acute subdural haematoma at the yaoundé central hospital: the need for landmarked burr holes. AJNS. 2011;30(2):19-27.

8. Hima-Maiga A. SY, Ndoye N., Ba M.C., Diallo M., Badiane S.B. Chronic subdural hematomas in Dakar: clinical, diagnostic, therapeutic and evolving features in the age of the scanner (a propos of 88 cases). Mali Med. 2008;23(4):116.

9. Mezue W.C. OSC, Chikani M.C., Erechukwu A.U.,. Changing trends in chronic subdural haematoma in Nigeria. Afr J Med Med Sci. 2011;40(4):373-6. 10. Mwanyombet Ompounga L. ALFC, Loembe P.M. Treatment of chronic subdural hematomas at libreville (Gabon): Review of 102 cases. AJNS. 2011;30(2):28-38.

11. World Bank. Benin: Country at a glance: http://www.worldbank.org/en/ country/benin; 2014 [december 26, 2014].

12. Markwalder TM. Chronic subdural haematoma: A review. Journal of neurosurgery. 1981;54:637-45.

13. Guénot M. Chronic Subdural Hematoma. Neurochirurgie. 2001;47(5):459- 
60.

14. Fatigba H.O. SdTMK, Tchaou B.A., Mensah E., Allode A.S., Padonou J., . Surgical Management of Head Trauma: Problems, Results, and Perspectives at the Departmental Teaching Hospital of Borgou, Benin. World Neurosurg. 2013:80:246-50.

15. Nayil K, Ramzan A, Sajad A, Zahoor S, Wani A, Nizami F, et al. Subdural hematomas: an analysis of 1181 Kashmiri patients. World Neurosurg. 2012;77(1):103-10.

16. Sousa EB, Brandao LF, Tavares CB, Borges IB, Neto NG, Kessler IM Epidemiological characteristics of 778 patients who underwent surgical drainage of chronic subdural hematomas in Brasilia, Brazil. BMC surgery. 2013;13:5.

17. Baechli H NA, Bucher HC, Gratzl O. Demographics and prevalent risk factors of chronic subdural haematoma: results of a large singlecenter cohort study. Neurosurg Rev. 2004;27(4):263-6.

18. Ito H, Komai T, Yamamoto S. Fibrinolytic enzyme in the lining walls of chronic subdural hematoma. Journal of neurosurgery. 1978;48(2):197-200.

19. Weir B. Oncotic pressure of subdural fluids. Journal of neurosurgery. 1980;53(4):512-5.

20. Yamamoto T, Sato S. Electron microscope studies on the vessel wall and the leucocyte emigration. Archivum histologicum Japonicum $=$ Nihon soshikigaku kiroku. 1966;27(1):297-310.

21. Yamashima T, Yamamoto S, Friede RL. The role of endothelial gap junctions in the enlargement of chronic subdural hematomas. Journal of neurosurgery. 1983;59(2):298-303.

22. Fujisawa H, Ito H, Kashiwagi S, Nomura S, Toyosawa M. Kallikrein-kinin system in chronic subdural haematomas: its roles in vascular permeability and regulation of fibrinolysis and coagulation. Journal of neurology, neurosurgery, and psychiatry. 1995;59(4):388-94.

23. Hirashima Y, Nagahori T, Nishijima M, Endo S, Takaku A, Nakagawa Y. Analysis of plasma and hematoma lipids related to choline glycerophospholipid in patients with chronic subdural hematoma. Neurologia medico-chirurgica. 1994;34(3):131-5.

24. Matsumori K, Yoshioka M. [Kinetics of prostaglandin and its significance in chronic subdural hematoma]. Neurologia medico-chirurgica. 1987;27(6):498504.

25. Nomura S, Kashiwagi S, Fujisawa H, Ito H, Nakamura K. Characterization of local hyperfibrinolysis in chronic subdural hematomas by SDS-PAGE and immunoblot. Journal of neurosurgery. 1994;81(6):910-3.

26. Suzuki K, Takano S, Nose T, Doi M, Ohashi N. Increased concentration of vascular endothelial growth factor (VEGF) in chronic subdural hematoma. The Journal of trauma. 1999;46(3):532-3.

27. Weigel R, Schilling L, Schmiedek P. Specific pattern of growth factor distribution in chronic subdural hematoma $(\mathrm{CSH})$ : evidence for an angiogenic disease. Acta neurochirurgica. 2001;143(8):811-8; discussion 9.

28. Bender MB. CN. Non surgical treatment of subdural hematomas. Arch Neurol 1974;31:73-9.

29. R. VJ. Definitive treatment of chronic subdural hematoma by twist-drill craniostomy and closed-system drainage. Neurochirurgie. 2001;47(5):479-87.

30. Putman TJ CH. Chronic subdural hematoma: its pathology, its relation to pachymeningitis hemorrhagica and its surgical treatment. Arch Surg 1925;11:329-93.

31. Grisoli F GN, Peragut J.C., . Perioperative lumbar injection of Ringer's lactate solution in chronic subdural haematoma: a series of 100 cases. Neurosurgery. 1988;23:616-21.

32. Sambasivan M. An overview of chronic subdural haematoma: experience with 2300 cases. Surgical neurology. 1997;47(5):418-22.

33. Hamilton MG FJ, Trammer BI. Chronic subdural haematoma: the role for craniotomy re-evaluated. Neurosurgery. 1993;33:67-72.

34. McKissock W RA, Bloom W.H. Subdural hematoma. A review of 389 cases. Lancet. 1960;1:1365-9.

35. Tabaddor K, Shulmon K. Definitive treatment of chronic subdural hematoma by twist-drill craniostomy and closed-system drainage. Journal of neurosurgery. 1977;46(2):220-6

36. Drapkin AJ. Endoscopy for chronic SDH. Surgical neurology. 1997;48(4):427.

37. Probst C. Peritoneal drainage of chronic subdural hematomas in older patients. Journal of neurosurgery. 1988;68(6):908-11.

38. Gazzeri R, Galarza M, Neroni M, Canova A, Refice GM, Esposito S. Continuous subgaleal suction drainage for the treatment of chronic subdural haematoma. Acta neurochirurgica. 2007;149(5):487-93; discussion 93.

\section{Comments}

Hode and colleagues presented their experiences on 104 cases of chronic subdural hematoma (CSDH) in the Benin in sub-Saharan Africa (1). They performed acceptable approach and management of CDSH which usually occurs after a mild trauma in old age. They had 3\% mortality, $4 \%$ morbidity and no recurrence. I would have a concern about no recurrence in 104 patients which might be due to loss to follow-up in some of their patients. We do not know if Hode and colleagues followed all their patients for 6-12 months. It seems they did not perform post- operative brain CT scan in all their patients. Observation of a death in one of their patients due to contralateral subdural hematoma, may confirm this hypothesis.

I congratulate our colleagues in Benin who helped their neurosurgical patients. My professor Leleand Albright and his wife wrote an interesting paper about life and surgery in West Africa (2). I also wrote my experiences in 12-13 years practice in the lowest socioeconomic province of Iran (3) and I believe we will publish so many valuable papers from Africa related to patients who refer to neurosurgeons very late and are more severe than what can be seen in developed countries.

Vafa Rahimi-Movaghar, MD, Professor of Neurosurgery, Sina Trauma and Surgery Research Center, Tehran University of Medical Sciences, Tehran, Iran

\section{References}

1. Hode L, Quenum K, Fatigba O.H, Fanou L, Lansdale G.S.H. Treatment and Outcome of Chronic Subdural Hematoma in Sub-Saharan Africa and the Country of Benin. IrJNS. 2015;1(2): 31-35.

2. Albright AL, Ferson SS. Developing pediatric neurosurgery in a developing country. J Child Neurol. 2012;27:1559-1564.

3. Rahimi-Movaghar V. Some challenging points for neurosurgeons in low-income developing countries. J Child Neurol. 2013 May;28(5):681-2. 